\title{
Journal of Management
}

http://jom.sagepub.com

\section{The Effects of Personal and Contextual Characteristics on Creativity: Where} Should We Go from Here?

Christina E. Shalley, Jing Zhou and Greg R. Oldham

Journal of Management 2004; 30; 933

DOI: $10.1016 /$ j.jm.2004.06.007

The online version of this article can be found at:

http://jom.sagepub.com/cgi/content/abstract/30/6/933

\author{
Published by: \\ @SAGE \\ http://www.sagepublications.com \\ On behalf of: \\ S.MPA

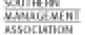 \\ Southern Management Association
}

Additional services and information for Journal of Management can be found at:

Email Alerts: http://jom.sagepub.com/cgi/alerts

Subscriptions: http://jom.sagepub.com/subscriptions

Reprints: http://www.sagepub.com/journalsReprints.nav

Permissions: http://www.sagepub.com/journalsPermissions.nav

Citations http://jom.sagepub.com/cgi/content/refs/30/6/933 


\title{
The Effects of Personal and Contextual Characteristics on Creativity: Where Should We Go from Here?
}

\author{
Christina E. Shalley* \\ College of Management, Georgia Institute of Technology, 800 West Peachtree Street, Atlanta, GA 30332, USA \\ Jing Zhou \\ Jesse H. Jones Graduate School of Management, Rice University, 6100 Main Street, Houston, TX 77005, USA \\ Greg R. Oldham \\ Department of Business Administration, University of Illinois at Urbana-Champaign, 270 Wohlers Hall, \\ 1206 South Sixth Street, Champaign, IL 61820, USA
}

Received 3 March 2004; received in revised form 14 June 2004; accepted 15 June 2004

Available online 14 July 2004

\begin{abstract}
This article systematically reviews and integrates empirical research that has examined the personal and contextual characteristics that enhance or stifle employee creativity in the workplace. Based on our review, we discuss possible determinants of employee creativity that have received little research attention, describe several areas where substantial challenges and unanswered questions remain, present a number of new research directions for theory building, and identify methodological improvements needed in future studies of creativity in organizations.
\end{abstract}

(C) 2004 Elsevier Inc. All rights reserved.

Considerable evidence now suggests that employee creativity can substantially contribute to organizational innovation, effectiveness, and survival (Amabile, 1996; Nonaka, 1991). When employees exhibit creativity at work, they produce novel, potentially useful ideas about organizational products, practices, services or procedures (Shalley \& Gilson, 2004). The presence of these creative ideas increases the likelihood that other employees will apply the ideas in their own work, further develop the ideas, and then transfer them to other individuals in the organization for their own use and development. It is the use and development of creative ideas that allows the organization to adjust to shifting market

\footnotetext{
* Corresponding author. Tel.: +1 404894 4922; fax: +1 4048946030.

E-mail addresses: christina.shalley@mgt.gatech.edu (C.E. Shalley), jzhou@ rice.edu (J. Zhou), g-oldham@uiuc.edu (G.R. Oldham).
} 
conditions, respond to opportunities, and thereby, to adapt, grow and compete (Nonaka, 1991; Oldham, 2002).

Given the potential significance of employee creativity, it is not surprising that a number of recent empirical studies have examined the personal and contextual factors that enhance or restrict it (e.g., Amabile, Schatzel, Moneta \& Kramer, 2004; Rodan \& Galunic, 2004; Tierney \& Farmer, 2002; Zhou, 2003). The purpose of this article is to review and integrate the results of this literature. Since most of the earlier research has addressed the determinants of creativity exhibited by individual employees, this will be the emphasis of our review. We provide a synthesis of what we currently know about creativity, and then suggest a number of new directions for creativity research.

\section{Background}

Over the past two decades, most theorists have defined creativity as the development of ideas about products, practices, services or procedures that are (a) novel and (b) potentially useful to the organization (see Amabile, 1996; Zhou \& Shalley, 2003). Ideas are considered novel if they are unique relative to other ideas currently available in the organization. Ideas are considered useful if they have the potential for direct or indirect value to the organization, in either the short- or long-term. Given this definition, creativity could range from suggestions for incremental adaptations in procedures to radical, major breakthroughs in the development of new products (Mumford \& Gustafson, 1988). The definition makes no assumptions about the relative value of incremental vs. radical ideas, and it may be that in some circumstances management might consider incremental ideas desirable, whereas in other circumstances more radical ideas might be valued. Finally, our definition assumes that creative ideas may be generated by employees in any job and at any level of the organization (Madjar, Oldham \& Pratt, 2002; Shalley, Gilson \& Blum, 2000).

Most studies have measured creativity using ratings by individuals who are believed to have advanced knowledge within the domain of interest. Specifically, laboratory studies have generally used expert judges to rate the creativity of ideas produced by research participants (e.g., Shalley, 1995; Zhou, 1998). By contrast, most field studies have relied upon supervisors to judge an employee's creativity (e.g., George \& Zhou, 2001; Tierney \& Farmer, 2002). Additionally, some field studies have included objective measures that may reflect creativity, such as, patent disclosures, technical reports, and ideas submitted to suggestion programs (e.g., Frese, Teng \& Wijnen, 1999; Oldham \& Cummings, 1996; Tierney, Farmer \& Graen, 1999).

It is important to distinguish creativity from innovation. Creativity refers to the development of novel, potentially useful ideas. Although employees might share these ideas with others, only when the ideas are successfully implemented at the organization or unit level would they be considered innovation (Amabile, 1996; Mumford \& Gustafson, 1988). Therefore, creativity might best be conceptualized as a first step that is necessary for subsequent innovation (West \& Farr, 1990). In this article, we focus exclusively on creativity.

Finally, we limit our review to published studies that (a) have included measures of creativity that match our definition (novel, potentially useful ideas), (b) have used samples from normal, adult populations, and (c) assessed variables that have clear implications for 
organizations. Personal or contextual factors are included in our review if they have been examined in a minimum of three published research investigations. In conducting our review, in order to be comprehensive in our coverage of the creativity literature, we searched PsychInfo and major journals in the field (e.g., Academy of Management Journal, Journal of Applied Psychology, Journal of Management, Organizational Behavior and Human Decision Processes, and Personnel Psychology).

\section{Employee Creativity: An Organizing Framework}

Our framework argues that creativity is a function of the employee's personal characteristics, the characteristics of the context in which he or she works, and also the interactions among these characteristics. The argument that personal and contextual characteristics interact with one another essentially asserts that certain contexts "match" individuals' personal characteristics and that this match results in high levels of employee creativity. This framework is derived from earlier theory on creativity that has emphasized the importance of person-context interactions (e.g., Amabile, 1996; Woodman, Sawyer \& Griffin, 1993), and from the broader literature on person-environment fit (e.g., Kristof, 1996; Schneider, 1987).

The personal characteristics described in our review include personality and cognitive style dimensions that have received substantial attention in the creativity literature. Both sets of characteristics are expected to affect individuals' creativity by influencing the extent to which they apply various strategies that may facilitate creative idea production. For example, individuals with certain personality characteristics may be especially effective at recognizing problems or at combining new information, which may enable them to produce more creative work. Thus, our review includes the studies that have examined the direct effects of personality and cognitive style variables on the creativity individuals' exhibit at work.

We broadly define contextual characteristics as dimensions of the work environment that potentially influence an employee's creativity but that are not part of the individual. As such, characteristics of the job, work setting, and relationships with coworkers and supervisors would all be considered contextual factors. Drawing on early theory and research (e.g., Amabile, 1996; Deci \& Ryan, 1985), we posit that each contextual characteristic affects creativity via its effects on employees' "intrinsic motivation" to perform a work assignment. Intrinsic motivation refers to the extent to which an individual is excited about a work activity and engages in it for the sake of the activity itself (Utman, 1997). Scholars have long argued that individuals are likely to be most creative when they experience high levels of intrinsic motivation (see Amabile, 1996) since such motivation increases their tendency to be curious, cognitively flexible, risk taking, and persistent in the face of barriers (Utman, 1997; Zhou \& Shalley, 2003) all of which should facilitate the development of creative ideas.

The expected effects of contextual characteristics on intrinsic motivation can be explained using Cognitive Evaluation Theory (Deci \& Ryan, 1985). This theory posits that all contextual factors have two aspects: informational and controlling. The relative salience of these aspects determines whether a contextual factor has positive or negative effects on 
intrinsic motivation. When the controlling aspect is more salient, individuals perceive that their thoughts, feelings, or actions are being constrained by the contextual factor itself and feel that they are no longer the origin of their own thoughts or actions. As a result, intrinsic motivation should diminish, and individuals would be expected to exhibit low levels of creativity. By contrast, when the informational aspect of a contextual factor is more salient, individuals perceive that the factor exerts little external pressure to achieve things in prescribed ways and provides relevant information about their personal competence. In this situation, individuals should feel supported and encouraged, resulting in enhanced intrinsic motivation and subsequent creativity.

Finally, our framework argues that to more fully understand creativity it is necessary to consider both interactions between personal and contextual characteristics and interactions among different contextual characteristics. Thus, in addition, to reviewing studies that have examined the direct effects of contextual and personal characteristics on creativity, we also review those that have examined the possibility that these contextual characteristics interact with one another to affect individuals' creative accomplishments. The argument for addressing person-context interactions is that individuals with certain personal characteristics are most likely to value the rewards and opportunities provided by particular contextual factors and, as a result, exhibit higher creativity when they are present. Further, the argument that contextual characteristics might interact with one another is that employees may be more likely to attend to or appreciate the qualities of one contextual variable when another contextual factor is simultaneously present.

\section{The Impact of Personal Characteristics on Creativity}

A large body of literature has examined the possibility that creativity is affected by a variety of individual difference characteristics (e.g., demographic and biographic variables) (Rodan \& Galunic, 2004; Schaefer, 1969; Tierney \& Farmer, 2002). Our review focuses on those characteristics that have received the most research attention-namely, individuals' personalities and cognitive styles.

\section{Personality}

Much of the early work examining the effects of personality used either Gough's (1979) Creative Personality Scale (CPS) or measures of one or more dimensions associated with the Five Factor Model of personality (FFM; Costa \& McCrae, 1992). The CPS measure is intended to provide an index of an individual's overall creative potential. Those who score high on the measure are expected to approach problems with broad interests that enable them to recognize divergent information and opinions (Barron \& Harrington, 1981). In addition, these individuals are thought to possess the self-confidence and tolerance for ambiguity to be patient with competing views, and to persist in developing their own original ideas.

Results of previous studies provide some support for the expected positive relation between CPS and creativity (Feist, 1998, 1999; Oldham \& Cummings, 1996; Zhou \& Oldham, 2001). For example, Gough (1979) found positive, significant correlations between 
the CPS and creativity ratings for 10 of 12 groups of individuals (e.g., architects and scientists).

All of the FFM dimensions (i.e., neuroticism, agreeableness, conscientiousness, extraversion, and openness to experience) have several components but research has found that they hang together as five relatively stable factors (see Feist, 1998). Studies that have examined the FFM dimensions have demonstrated that each is connected to individuals' creativity. However, the FFM dimension that has been most consistently related to creativity is openness to experience (Feist, 1998, 1999). Individuals high on the openness dimension are those who are broad minded, curious, and untraditional. By contrast, those low on openness tend to be conventional, unartistic, and unanalytical. Moreover, McCrae and Costa (1997) argue that open individuals are both more flexible in absorbing information and combining new and unrelated information, and also have a higher need to seek out unfamiliar situations that allow for greater access to new experiences and perspectives.

As indicated above, results of earlier studies show that openness to experience generally relates positively to creativity across a variety of domains (Feist, 1998). For example, a recent study of creativity in organizations showed a positive, significant correlation between openness to experience and creativity as rated by managers (Scratchley \& Hakstian, 2000). Research has also shown that measures of openness correlate positively with CPS (McCrae, 1987; Piedmont, McCrae \& Costa, 1991).

\section{Cognitive Style}

Early theory suggests that individuals' cognitive style might have a direct effect on their creativity (Amabile, 1996; Woodman et al., 1993). The approach to understanding and measuring cognitive style that has received the most attention in the literature is based on Kirton's $(1976,1994)$ Adaption-Innovation Theory. This theory posits that individuals have a natural orientation or a preferred means of creative problem solving. Specifically, Kirton proposes a bipolar continuum of cognitive styles with adaptors and innovators being located at opposite ends. Individuals with an adaptive cognitive style (adaptors) tend to operate within given paradigms and procedures without questioning their validity, whereas those with an innovative style (innovators) tend to be more willing to take the risk of violating the agreed-upon way of doing things in order to develop problem solutions that are qualitatively different from previous ones.

A number of investigations have examined the relation between individuals' cognitive style and creative outcomes (see Kirton, 1994; Masten \& Caldwell-Colbert, 1987). Results suggest that individuals with an innovative style tend to be more creative than those with an adaptive style (e.g., Keller, 1986; Lowe \& Taylor, 1986). For example, Tierney et al. (1999) showed that an innovative cognitive style was predictive of two indicators of employee creativity (supervisory ratings and number of research reports).

Although a few previous studies have shown significant relations among measures of cognitive style and personality (see Kirton, 1994; Kwang \& Rodrigues, 2002), previous research has not examined whether cognitive style and personality make independent contributions to creativity or whether they interact with one another to affect individuals' creative responses. This is a potentially fruitful topic for future research that would allow 
us to determine if individuals with particular personality profiles are most creative if they also possess a certain cognitive style.

\section{The Impact of Contextual Characteristics on Creativity}

Next, we review those contextual characteristics that have received attention in the literature, and explain how each characteristic might affect creativity based on the intrinsic motivation perspective described earlier. The characteristics we examine here are (a) job complexity; (b) relationship with supervisors; (c) relationship with coworkers; (d) rewards; (e) evaluation; (f) time deadlines and goals; and (g) spatial configurations of work settings.

\section{Job Complexity}

The design of jobs has long been considered an important contributor to employee creativity (West \& Farr, 1990). When individuals work on complex jobs (i.e., those characterized by high levels of autonomy, feedback, significance, identity and variety) (Hackman \& Oldham, 1980) they are likely to experience high levels of intrinsic motivation and to respond to this motivation by developing creative ideas. Specifically, complex jobs should enhance individuals' excitement about their work activities and their interest in completing these activities, and this excitement should foster creativity.

Previous studies provide results that are generally consistent with these arguments (e.g., Amabile \& Gryskiewicz, 1989; Farmer, Tierney \& Kung-McIntyre, 2003; Oldham \& Cummings, 1996). For example, Tierney and Farmer (2002, 2004) showed positive, significant relations between supervisory ratings of creativity and objective measures of employees' job complexity derived from the Dictionary of Occupational Titles (Roos \& Treiman, 1980). Also, Hatcher, Ross and Collins (1989) found significant relations between employee self-reports of job complexity and the number of creative ideas they submitted to an organization suggestion program.

\section{Relationship with Supervisors}

Numerous studies have examined relations between a supervisor's leadership style and employee creativity. Following the intrinsic motivation perspective, supportive leadership styles are expected to boost intrinsic motivation, whereas those that are controlling in nature are expected to diminish intrinsic motivation and creativity (Deci \& Ryan, 1985). When supervisors are supportive they show concern for employees' feelings, provide nonjudgmental, informational feedback about their work, and encourage them to voice their own concerns (Deci, Connell \& Ryan, 1989). By contrast, controlling supervisors closely monitor employee behavior, make decisions without involving employees, and generally demand that employees follow strict rules and guidelines (Deci et al., 1989).

Although a few studies have failed to show significant relations between supervisory support and employee creativity (e.g., George \& Zhou, 2001; Zhou, 2003), the vast majority of 
earlier studies provide substantial support for the expected relations between supportive and controlling leadership styles and creativity (e.g., Amabile \& Conti, 1999; Amabile et al., 1996, 2004; Amabile \& Gryskiewicz, 1989; Andrews \& Farris, 1967; Madjar et al., 2002; Oldham \& Cummings, 1996; Shalley \& Gilson, 2004; Tierney \& Farmer, 2002, 2004; Zhou $\&$ George, 2003). For example, Frese et al. (1999) demonstrated that the more supervisors encouraged employees, the more creative ideas they submitted to the organization's suggestion program. Shin and Zhou (2003) found positive relations between "transformational" leadership (i.e., providing intellectual stimulation, individualized consideration, and inspirational motivation) and creativity measures. Stahl and Koser (1978) found negative relations between supervisors' controlling behavior and R\&D scientists' creative output. Similarly, George and Zhou (2001) and Zhou (2003) showed that controlling behavior (i.e., close monitoring) on the part of supervisors was negatively related to employee creativity.

\section{Relationship with Coworkers}

Just as supportive, noncontrolling supervisory behavior is expected to boost employees' intrinsic motivation and creativity, analogous behaviors on the part of employees' coworkers are expected to have similar effects. That is, employees are expected to exhibit high levels of creativity when their coworkers are nurturing and supportive, since such behavior enhances intrinsic motivation. Conversely, nonsupportive, competitive coworkers should undermine intrinsic motivation and lower creativity.

Previous research provides only mixed support for these arguments (Amabile \& Gryskiewicz, 1989; Cummings \& Oldham, 1997; Madjar et al., 2002; McGlynn, Gibbs $\&$ Roberts, 1982; Torrance, 1965). For example, Amabile et al. (1996) found that individuals in work teams were more creative when their coworkers were supportive and encouraging. Similarly, Zhou and George (2001) showed positive, significant relations between employee creativity and coworker support and informational feedback. However, other studies failed to support these arguments. George and Zhou (2001) found nonsignificant relations between employee creativity and the extent to which coworkers provided constructive "helping" at work or inaccurate communication. Van Dyne, Jehn and Cummings (2002) found a nonsignificant relation between creativity and "work strain" (i.e., the extent to which the employee argued with members of his or her work group and experienced conflict with them). Finally, Shalley and Oldham (1997) showed that individuals in competition with others generated ideas higher in overall creativity than those who were not in competition.

\section{Rewards}

Although the effect of contingent rewards (e.g., monetary incentives and recognition) on individuals' creativity has received much research attention (Amabile, 1996; Eisenberger, 1992), there is little agreement among scholars concerning the likely direction of the effects of such rewards. That is, some authors argue that contingent rewards serve to control individuals' behavior, thereby resulting in diminished intrinsic motivation and creativity (Amabile, 1996). Others argue that such rewards boost creativity because rewards have 
informational value and recognize individuals' personal competencies (Eisenberger, 1992; Eisenberger \& Armeli, 1997).

Early empirical research has done little to sort out which of these positions is valid, and support has been found for both positions (e.g., Amabile, Hennessey \& Grossman, 1986; George \& Zhou, 2002). For example, Eisenberger and Rhoades (2001) showed that story titles produced by college students who were promised money were significantly more creative than the titles of students not promised rewards. Conversely, Kruglanski, Friedman and Zeevi (1971) showed that college students not promised a reward exhibited higher creativity on two tasks than those who were promised rewards.

\section{Evaluation}

A number of early studies examined the effects of anticipated evaluation of an individual's work on the creativity of that work (Zhou \& Shalley, 2003). Most of this earlier work focused on the effects of an anticipated judgmental evaluation that is, an evaluation that critically assessed the creativity of an individual's work and contrasted it to some standard (Oldham, 2002). A smaller set of studies examined the effects of an anticipated developmental evaluation (i.e., an evaluation that is nonjudgmental and intended to facilitate the development of an individual's skills) (Shalley, 1995). Following the intrinsic motivation perspective, it is expected that individuals would experience judgmental evaluations as controlling. Consequently, they should focus their attentions on the evaluation rather than on their work activities; this would result in lowered intrinsic motivation and subsequently lower creativity. Conversely, individuals should experience developmental evaluations as supportive and informational, and therefore exhibit higher creativity.

Previous studies provide results that are generally consistent with the argument that creativity is lower when individuals expect their work to be critically judged. Moreover, these effects tend to emerge regardless of the source that is expected to conduct the evaluation (e.g., experimenters, experts, computers, or the individual him/herself) (Bartis, Szymanski \& Harkins, 1988; Cheek \& Stahl, 1986; Szymanski \& Harkins, 1992). For example, Amabile (1979) showed that individuals who expected their artwork to be critically evaluated by experts submitted less creative work than individuals in no-evaluation conditions. Likewise, Amabile, Goldfarb and Brackfield (1990) showed that the creativity of poems and collages was significantly lower among individuals expecting a judgmental evaluation of their work than of those expecting no critical evaluation.

Studies that focused on the effects of developmental evaluation typically produced results showing its positive effect on creativity (Shalley, 1995; Zhou \& Oldham, 2001). For example, Shalley and Perry-Smith (2001) demonstrated that the creativity of individuals who anticipated a judgmental evaluation was significantly lower than those expecting a developmental evaluation (i.e., experts would review individuals' work and provide suggestions for alternative approaches to be considered in the future). In addition, Zhou (1998) demonstrated that evaluative feedback on a preliminary task that was delivered in a developmental, informational style (i.e., "You did very well. Congratulations! Keep up the good work.") yielded higher creativity on a subsequent task than early task feedback provided in a controlling fashion (i.e., "You did very well, just as you should. But remember, you must keep your creativity at this level so that we can use your data"). 


\section{Time Deadlines and Goals}

The presence of time deadlines or production goals has often been mentioned as a possible constraint on creativity (see Amabile, 1996). When tight deadlines or production goals are present, individuals are expected to feel pressured to meet these deadlines or goals, resulting in lowered intrinsic motivation and creativity (Amabile, Hadley \& Kramer, 2002).

Previous studies provide only mixed results for these expected effects (e.g., Amabile et al., 1996; Amabile \& Gryskiewicz, 1989; Carson \& Carson, 1993; Shalley, 1995; Soriano de Alencar \& Bruno-Faria, 1997). For example, Shalley (1991) found that creativity was low when individuals were given either a "do-your-best" or difficult productivity goal. Andrews and Smith (1996) showed a negative relation between experienced time pressure and the creativity of ideas produced by marketing professionals. However, Andrews and Farris (1972) found positive, significant relations between scientists' experienced time pressure and their creativity. Finally, Kelly and McGrath (1985) found that products generated by individuals working under a 10-minute time limit were less creative than those working under a 20-minute limit.

There is some evidence that the presence of a different type of goal a creativity goal (e.g., $90 \%$ of the ideas you generate should be creative) might have positive effects on employee creativity and mitigate the effects of production goals (Carson \& Carson, 1993; Shalley, 1995). For example, Shalley (1991) showed that individuals assigned to both "doyour-best" and difficult productivity goal conditions exhibited higher creativity if either a do-your-best or difficult creativity goal also was assigned. It may be that a creativity goal causes individuals to focus their attention on the task itself, and allows them to disregard the pressure from a production goal or deadline.

\section{Spatial Configuration of Work Settings}

A few studies have examined the possibility that dimensions of a setting's spatial configuration (e.g., number of physical boundaries present in the setting, distance between individuals in the setting, and the overall density of the setting [i.e., number of individuals per unit of space]) might have a substantial impact on individuals' creativity (Aiello, DeRisi, Epstein \& Karlin, 1977; Shalley \& Oldham, 1997). Early work established that individuals who worked in dense settings with few boundaries experienced more unwanted or unexpected interpersonal intrusions, which then affected their attitudes and behaviors (Oldham, Cummings \& Zhou, 1995; Sundstrom, 1986). It may also be that the unexpected interruptions present in dense settings distract individuals' attention from the work itself, lowering their intrinsic motivation and thereby diminishing creativity.

Results of earlier research provide some support for this position. For example, Aiello et al. (1977) showed that individuals working in low spatial density areas exhibited higher performance on a creativity task than individuals in higher density areas. An interview study by Soriano de Alencar and Bruno-Faria (1997) found that employees mentioned "inadequate physical environment" (i.e., lack of space and presence of noise) as a factor that inhibited their creativity. Finally, Shalley and Oldham (1997) showed that when competitors were present, individuals who worked in a room without physical boundaries exhibited lower creativity than those who worked in a room with boundaries. 


\section{Conclusions: Contexts and Creativity}

Our review suggests that several contextual characteristics have consistent, significant effects on individuals' creativity and that the direction of these effects is in line with the intrinsic motivation perspective. Specifically, individuals tend to exhibit high creativity when: their jobs are complex, their supervisors engage in supportive, noncontrolling behaviors, their work is evaluated in a developmental, nonjudgmental fashion, and their setting's configuration restricts unwanted intrusions. However, the picture is less clear with regard to the effects on creativity of other characteristics reviewed. Although some studies suggest that individuals exhibit high creativity when coworkers are supportive, contingent financial rewards are absent, and few time deadlines or production goals are present, other studies show that these characteristics have either nonsignificant effects or significant effects that are opposite in direction of those expected by the intrinsic motivation perspective.

There are several possible explanations for these inconsistent results. First, it is possible that contextual characteristics differ in the extent to which they provide clear and salient informational or controlling cues to individuals. That is, it may be that contextual characteristics shown to have generally consistent effects on creativity (e.g., job complexity) provide less ambiguous cues about an individual's personal competencies than do those shown to have inconsistent effects (e.g., contingent rewards). Second, based on the person-context interaction perspective discussed earlier, it may be that the effect of a given contextual characteristic on creativity is a function of the employee's personal characteristics (e.g., personality). For example, individuals with certain personalities may respond negatively to contingent rewards, whereas individuals with different personality profiles might respond quite positively, thereby explaining the inconsistent effects of this contextual dimension described earlier. Finally, it may be that the mixed results are a function of the presence (or absence) of multiple, competing contextual conditions. For example, it may be that the controlling aspect of time deadlines is highly salient when a second contextual factor is present, resulting in lowered creativity. However, when this second factor is absent, the controlling aspect might be less salient and time deadlines have weaker effects.

The latter two explanations for the inconsistent results involving contextual characteristics and creativity essentially argue that contextual characteristics may interact with individuals' personal characteristics or with other contextual characteristics to affect creativity. Both of these possibilities are examined in the section below. Specifically, in this section we examine the literature that has investigated the extent to which personal and contextual characteristics interact with one another to affect employee creativity. In addition, we review the few studies that have examined the effects of interactions involving two or more contextual characteristics.

\section{Interactions Among Personal and Contextual Characteristics}

A few studies have examined the possibility that contextual factors interact with either individual's personality or with their cognitive styles. Most of the work addressing employee 
personality has focused on the CPS or on openness to experience (George \& Zhou, 2001; Oldham \& Cummings, 1996). The authors of these studies argued that those who score high on CPS or openness value contextual conditions that support creativity (e.g., supportive supervision) and respond to these conditions by exhibiting high creativity. Conversely, those who score lower on openness or CPS tend to devalue these conditions and respond less positively to them.

Results provide mixed support for these arguments. For example, Oldham and Cummings (1996) found that high CPS employees, who worked on complex jobs, and were supervised in a supportive, noncontrolling fashion, had the highest numbers of patent disclosures and high creativity ratings. Similarly, Zhou and Oldham (2001) showed that individuals who were high on CPS and expected a developmental assessment of their work had the highest creativity. George and Zhou (2001) showed that individuals who were open to experience responded positively when they received positive supervisor feedback and had flexibility in their work roles. However, two studies showed that CPS had moderating effects different than expected. Zhou (2003) found that employees with low CPS exhibited higher creativity when creative coworkers were present and supervisory behavior was noncontrolling than when creative coworkers were present and supervisors engaged in controlling behavior. Madjar et al. (2002) found that CPS did not moderate the relation between supervisor/coworker support and creativity, but that it did influence relations involving support from family/friends. Those with low CPS responded most positively to this support.

Only two studies have examined interactions between cognitive style and contextual conditions and both showed that style had significant moderating effects. Tierney et al. (1999) found that employees' with an adaptive cognitive style produced the greatest number of invention disclosure forms when they had supportive, high-quality relationships with their supervisors. Baer, Oldham and Cummings (2003) found a positive relation between contingent rewards and creativity for employees with an adaptive style who worked on simple jobs. Those with an innovative style in complex jobs were generally unaffected by extrinsic rewards. Finally, those in the adaptive style/complex job or innovative style/simple job conditions exhibited lower creativity as extrinsic rewards increased.

In addition to studies that have examined interactions among personal and contextual characteristics, a few studies have examined interactions between one or more of the contextual characteristics reviewed (e.g., Baer et al., 2003; Shalley, 1991; Van Dyne et al., 2002). For example, Shalley and Oldham (1997) argued that expected negative effects of competition on creativity depended upon whether competitors were visible, since their visibility might increase the salience of the competition's controlling aspect. Results provided some support for this argument by showing that individuals who competed with others present in the same room exhibited lower creativity when these others were visible vs. in conditions in which they were not visible. Zhou (2003) showed that both noncontrolling and supportive behavior on the part of supervisors had stronger, positive effects on creativity when coworkers were present in the work unit who exhibited high creativity. These results may indicate that the informational aspect of supervisory behavior was more salient when creative coworkers were present because such behavior provided individuals a clear roadmap to achieve the creativity they observed in others. 
The studies reviewed above suggest that inconsistent context-creativity relations might be explained by considering other contextual conditions. It is also possible that the effects of contextual characteristics shown to have consistent effects on creativity might be further amplified by simultaneously considering other contextual conditions. For example, it may be that the informational properties of a characteristic such as job complexity will become even more salient when a second contextual characteristic is present that reinforces these informational properties. A few studies have examined this possibility and provide results consistent with this argument (Oldham \& Cummings, 1996; Shalley \& Perry-Smith, 2001). For example, Zhou (1998) examined interactions between feedback style (informational and controlling) and feedback type (positive and negative). Results demonstrated that positive feedback delivered in an informational style produced the highest creativity and negative feedback provided in a controlling style the lowest. Likewise, Shalley (1995) found that creativity was highest when individuals had a creativity goal, worked alone in a private room, and anticipated receiving a developmental evaluation of their work.

In summary, results suggest that employees' personality and cognitive style do influence the way they respond to contextual factors. Also, different contextual characteristics have been found to interact with one another in influencing employee creativity. However, more research is needed. First, since previous research focused on only a limited number of contextual factors (e.g., supervisory style), work is needed to examine whether other conditions (e.g., judgmental evaluation) interact with personality or cognitive style variables. Second, work is needed to sort out the seemingly conflicting results obtained for the CPS and openness to experience personality measures. Perhaps including direct measures of employee values and assessing the extent to which contextual factors actually provide support and competence information to employees would allow us to better understand these conflicting results. Third, research is needed that examines the effects of personal characteristics not discussed in this article. For example, employees' "growth need strength" has been shown to moderate the effects of complex jobs on employee outcomes such as performance and job satisfaction (Hackman \& Oldham, 1980). It may be that it also influences employees' creative responses to complex jobs. Also, further studies are needed that examine interactions among multiple contextual characteristics. For example, do job complexity, supervisory support and spatial configuration measures interact with one another to affect creativity? And do other conditions affect the way individuals respond to contextual characteristics discussed above? For example, it may be that contingent, extrinsic rewards have strong negative effects on creativity only when organizational norms are present that suggest that such rewards are inappropriate (see Staw, Calder, Hess \& Sandelands, 1980). Finally, work is needed to examine the joint moderating effects of individual characteristics (e.g., cognitive style and personality) on relations between employee creativity and a variety of contextual conditions.

\section{New Directions in Creativity Research}

In this section we discuss a number of new directions for creativity research. Unlike much of the research reviewed, many of these new directions take very different approaches to 
understanding creativity that are not directly related to the person, context, and interactionist perspective that has served to organize our literature review. All, we believe, hold substantial promise for future research.

\section{Intrinsic Motivation as a Mediator}

We argued throughout this article that contextual conditions influence creativity via their effects on employees' intrinsic motivation. Although this perspective has often been discussed in the literature (see Amabile, 1996), few studies have directly tested it. That is, many of the studies reviewed provide results consistent with the argument that contextual factors affect creativity via their effects on individuals' intrinsic motivation, yet few studies actually measured intrinsic motivation and tested whether it empirically mediates the context-creativity relation (Zhou \& Shalley, 2003). Moreover, the studies that have examined the mediating role of intrinsic motivation provide results that are rather inconsistent (e.g., Amabile, 1979; Amabile et al., 1990). For example, Shin and Zhou (2003) found that a measure of intrinsic motivation only partially mediated the relation between transformational leadership and creativity. In addition, Shalley and Perry-Smith (2001) found no significant mediation for intrinsic motivation in the relation between expected evaluation and creativity.

One explanation for these relatively weak mediating effects involves the measures of intrinsic motivation used in the previous investigations. It may be that the questionnaire measures that have been used to tap the intrinsic motivation construct are inadequate and that alternative measures should be developed and tested. Another possibility is that contextual characteristics do not affect creativity via intrinsic motivation but rather via alternative mediating conditions. One such mediator, employee positive mood states, is discussed below. Finally, it could be that high intrinsic motivation is important for creativity but that it needs to exist along with other intervening variables to have a significant effect on creativity. Research is now needed to investigate these possibilities by including a variety of measures of intrinsic motivation and other potential mediators, and contrasting the extent to which they explain relations between contextual conditions and creativity.

\section{Mood States}

Researchers and theorists have begun to examine the possible effects of employees' mood states on their creativity (see Isen, 1999; Madjar et al., 2002). Moods are pervasive generalized affective states that are relatively transient in nature, are experienced over the short run, fluctuate, and may be affected by contextual factors (George \& Brief, 1992). Previous work suggests that mood consists of two separate dimensions: positive (emotions ranging from high to low levels of excitation and elatedness) and negative (feelings of distress and fear) (Burke et al., 1989).

Much of the prior work in this area focused on positive mood. It suggests that when individuals experience positive moods, their cognitive or motivational processes are enhanced and their creative thinking and problem solving skills are facilitated (Hirt, Levine, McDonald \& Melton, 1997). Isen (1999) argued that when individuals experience positive moods, they make more connections between divergent materials, use broader categories, 
and see more associations among stimuli. As a result, individuals may be more likely to recognize a problem and to integrate a variety of resources, resulting in higher creativity. Moreover, it has been suggested that positive mood mediates the relation between contextual factors and creativity (Madjar \& Oldham, 2002; Madjar et al., 2002). For example, a field study showed that positive mood mediated relations between supervisor and coworker support and employees' creativity (Madjar et al., 2002).

A few studies suggest that even negative mood may play a role in employee creativity (e.g., George \& Zhou, 2002; Kaufmann \& Vosburg, 1997). For example, Zhou and George (2001) theorized that under certain conditions, negative job affect (i.e., job dissatisfaction) might be positively related to employee creativity. They argued that negative job affect or moods do not automatically lead to creativity; rather their impact is context dependent. When negative job affect signals that the status quo is no longer acceptable, under certain conditions (e.g., high continuance commitment and useful feedback from coworkers), it will trigger employees' desire to voice - to come up with new ways of doing things, thereby facilitating creativity. Results of their study supported this perspective. Further, George and Zhou (2002) found that under certain conditions (i.e., high perceived recognition and rewards for creativity and clarity of feelings), negative moods foster creativity and positive ones do not.

More research is now needed to examine the effects of positive and negative mood states on employees' creativity. As noted above, this work should compare and contrast the mediating effects of positive mood with that of intrinsic motivation. Research also should attempt to identify the entire set of conditions that need to be present if negative moods are to boost employee creativity.

\section{Self-efficacy and Creative Role Identity}

Researchers have begun to examine how individuals' views of themselves might translate to creativity. For example, Redmond, Mumford and Teach (1993) demonstrated that individuals' self-efficacy (i.e., the extent that individuals' believe they have the ability to accomplish task specific goals and objectives) (Bandura, 1977) was positively related to their creativity. Recently, Tierney and Farmer $(2002,2004)$ extended this work and developed the construct of "creative self-efficacy" (i.e., extent to which employees believe they have the ability to produce creative outcomes). In two field studies, results showed that creative self-efficacy was positively related to creativity, above and beyond contributions of general job self-efficacy. Additionally, Farmer et al. (2003) examined relations between creativity and creative role identity (i.e., whether an individual views him- or herself as a creative person). Results showed that creative role identity was predicted by self-views of creative behaviors, coworker creativity expectations, and high levels of exposure to US culture, with the highest creativity occurring when employees had a strong creative role identity and perceived that their organization valued creative work.

More work is now needed to further examine the effects of employees' self-views on their creativity. This research might include more established measures of personality and cognitive style to determine if creative efficacy contributes to creativity above and beyond these other measures. Finally, work is needed to determine if these two concepts have similar 
effects across all contextual conditions, or if effects are stronger in some contexts than in others.

\section{Creative Role Models}

A few recent studies have examined the effects of the presence of "creative role models" (e.g., coworkers or supervisors engaged in creative activities) on employee creativity (Shalley \& Perry-Smith, 2001; Zhou, 2003). Using social cognitive theory (Bandura, 1986) to develop a social learning perspective, Shalley and Perry-Smith (2001) hypothesized and found that observing creative models allows individuals to acquire relevant strategies and approaches that enables them to exhibit higher creativity in their own work. Possessing creativity-relevant skills and strategies increases the likelihood that one identifies the right problem, generates a variety of ideas, and uses appropriate standards to evaluate and refine the ideas. Observing creative model's behavior patterns, modes of thought, and standards of work may facilitate the observer's acquisition of creativity-relevant skills and strategies, thus promoting creativity.

Recent research supports this perspective. In two field studies, Zhou (2003) showed that the presence of creative coworkers had positive effects on creativity when supervisors engaged in either noncontrolling or supportive behavior, and that this effect was stronger for employees with low CPS. Research is now needed to determine the specific strategies and approaches individuals acquire when they are exposed to creative models, and the extent to which these strategies become a permanent part of their repertoire after exposure.

\section{Creative Process}

As described earlier, most of the research has defined creativity as an outcome (i.e., novel, potentially useful ideas). However, several scholars (e.g., Csikszentmihalyi, 1997; Drazin et al., 1999; Mainemelis, 2001; Mumford, 2000) have suggested that there is value in understanding the way in which individuals come to develop creative ideas. For example, they may link ideas from multiple sources, delve into unknown areas to find better or unique approaches to a problem, or seek out novel ways of performing a task. Considerable theoretical work (e.g., Amabile, 1996; Stein, 1967) has suggested that the creative process involves several stages, including (1) identifying a problem/opportunity, (2) gathering information or resources, (3) generating ideas and (4) evaluating, modifying, and communicating ideas. A number of studies have specifically focused on examining various cognitive processes or skills involved in creative problem solving (see Reiter-Palmon \& Illies, 2004 for a review). Some of the skills examined in these studies include problem finding, problem construction, combination, generation of alternatives, and idea evaluation, that are part of the creative process (e.g., Mumford, Baughman, Maher, Costanza \& Supinski, 1997; Reiter-Palmon, Mumford, Boes \& Runco, 1997; Vincent, Decker \& Mumford, 2002). Some recent empirical research has focused more on examining employees overall engagement in creative processes at work (e.g., Gilson, Mathieu, Shalley \& Ruddy, in press; Gilson \& Shalley, 2004; Kazanjian, Drazin \& Glynn, 2000).

Research is now needed that focuses on the different stages of creativity and what personal and contextual characteristics may be most desirable at each stage. For example, it may 
be that individuals who are high on openness to experience are most likely to generate creative ideas, while those who are extraverted are most likely to communicate these ideas to colleagues. If this were the case, it would suggest the profile of an employee likely to pass through the appropriate stages and produce creative work namely, individuals who were both open and extraverted. Or, it may be that individuals exhibit high levels of creativity when the context facilitates both idea generation (e.g., via a formal program that recognizes new ideas) and idea communication (e.g., via the absence of external evaluation). Thus, understanding the process and stages of creativity may suggest an emphasis on certain personal and contextual characteristics and a de-emphasis on others.

\section{Creativity in International Contexts}

The vast majority of the studies that we have reviewed examined the effects of personal and contextual characteristics on the creativity of employees who worked in organizations located in the US or other "Western" nations. Yet, earlier theoretical and empirical work suggests that individuals from non-Western cultures may respond differently to organizational conditions than those from Western nations (Anderson, De Dreu \& Nijstad, 2004; England \& Harpaz, 1990).

A recent study by Shin and Zhou (2003) suggests that there may be value in considering the international context in which creative work is produced. This study examined whether the cultural value of "conservation" (i.e., one favors propriety and harmony in interpersonal and group relations) (Schwartz, 1992) moderated the relation between transformational leadership and creativity. Using a sample of employees from organizations in Korea, they showed that transformational leadership had a stronger, positive relation to creativity for employees high on conservation (i.e., valuing tradition, conformity, and security) than for those low on conservation, suggesting that employees high on conservation were more willing to accept their leaders' influence and exhibited greater creativity in response to this influence. One interesting implication of their study is that the meaning and function of conservation may be different in Korea than in Western societies. Since Korean employees may focus on acting according to their social roles, conforming to expectations, and on maintaining good relationships with their superiors (Cha, 1994), employees high on conservation may be more willing to accept their leaders' suggestions for using other types of strategies which might enable them to exhibit higher creativity. That is, when their leaders exhibit transformational leadership, employees high on conservation readily accept such influences by becoming more excited and motivated to be creative.

These results highlight the need to conduct cross-cultural creativity studies. For example, research is needed that examines whether conservation values differ by country and whether conservation moderates the effects of contextual conditions for employees from US firms. Also, research that identifies what personal and contextual conditions are most relevant to individuals in different cultures is warranted. For example, different cognitive styles may be preferable for different cultures. Also, the importance of creative role identity across different cultures remains to be examined. The aforementioned Farmer et al. (2003) investigation examined creative role identity in Taiwan, which has a more collectivistic culture. If this concept were examined in an individualistic culture, such as the US, it may have different effects on employees' creativity. 


\section{Social Networks}

Most of the research reviewed here has examined the effects of contextual characteristics that are associated with the organization or setting in which the employee works. However, early research established that conditions outside of the employees' department or the boundaries of the organization can influence individuals' responses in the workplace (Oldham, 2002). Recently, attention has focused on how formal and informal social interactions with others who are not necessarily directly connected to an employee's job (e.g., in their professional or social network) may have an impact on their creativity (e.g., Madjar et al., 2002; Perry-Smith \& Shalley, 2003).

Using concepts from social network theory, Perry-Smith and Shalley (2003) argued that "weaker ties" (i.e., more distant relationships, such as acquaintances or distant colleagues) might be more beneficial for creativity than stronger ties (i.e., good friends or close relationships) because novel, nonredundant information from diverse social circles is more likely to be communicated through weak ties. Such information should help inform the ideas, processes and procedures employees in weak-tie networks develop at work. Perry-Smith and Shalley also argued that individuals' positions in their own network, as well as the connections they have outside their network, could influence their creativity. Specifically, they proposed that employees in peripheral positions with many connections outside their network would be exposed to new ideas and perspectives that contribute to their own creative ideas.

Research is now needed to test these propositions, as well as examining how location in networks may be associated with the personal and contextual conditions described in our review. For example, are certain personalities more likely to have strong or weak ties? Do individuals with different personalities or cognitive styles respond differently to network positions and exhibit different levels of creativity as a function of the network position-person match?

\section{Different Types of Creativity}

Throughout this paper, and in the extant literature, the concept of creativity is generally discussed as if it were a unitary construct. However, as stated earlier in our definition of creativity, it is recognized that creative ideas can range from minor adaptations to radical breakthroughs (Mumford \& Gustafson, 1988).

In a recent conceptual piece, Unsworth (2001) argued that the common definition used for creativity implies that creativity is really only one construct without considering the type of idea, why it was generated, or how the process began. She developed a matrix of four creativity types that varied on two dimensions: what was the driver for the engagement (external or internal) and what was the problem type (open or closed). Open ideas are those ideas that are discovered by the individual, while closed ideas are presented to the individual. The four creativity types are: responsive (closed, external), expected (open, external), contributory (closed, internal), and proactive (open, internal). Unsworth argued that there might be differences in processes and predictors for each of these types of creativity. For example, she suggested that internally driven ideas might need to be "sold" more to evaluators in order to make sure they are not dismissed, since they may not be recognized as 
needed at that time. Research is now needed that empirically tests these ideas. For example, do certain personal or contextual factors have differential effects depending on the type of creativity examined?

\section{The Measurement of Creativity}

As discussed earlier, most previous studies have measured creativity using ratings provided by other individuals. In particular, laboratory studies have used the consensual assessment technique (Amabile, 1996) in which two or more expert judges rate the overall creativity of each solution or product generated by a research participant. Such an approach allows for an evaluation of the inter-judge reliability of creativity ratings. If these ratings achieve acceptable levels of reliability, a creativity score is then computed as an average of the creativity ratings for each individual across the generated solutions (e.g., Shalley \& Perry-Smith, 2001; Zhou, 1998).

An alternative approach that has been less widely used is to have multiple judges evaluate the two components of creativity originality and usefulness. If the judges' ratings of these two constructs are reliable, separate originality and usefulness scores are computed for each participant by averaging each of the ratings, respectively. Then, a composite creativity index is formed for each participant by combining the originality and usefulness scores (Zhou \& Oldham, 2001). Although both of the above approaches provide creativity measures that are consistent with the definition of creativity, future research needs to examine the relative effectiveness of these two approaches. In addition, research is needed that examines the extent to which expert ratings converge with self-ratings of creativity made by the research participants themselves.

A different approach has been followed in field studies of creativity. In most of these studies, a single supervisor has rated each employee's overall creativity using one of three scales: (a) Oldham and Cummings' (1996) 3-item scale; (b) Tierney and colleagues' (1999) 9-item scale; or (c) George and Zhou's (2001) 13-item scale (e.g., Madjar et al., 2002; Tierney $\&$ Farmer, 2004). Systematic research is now needed to evaluate the relative strengths and weaknesses of these different scales in terms of their ability to accurately and reliably assess creativity. Moreover, future field studies should include evaluations of each employee's creativity by multiple judges (e.g., coworkers, other supervisors, and self) in order to assess inter-rater reliability.

In addition, although many field studies have found similar results involving supervisory ratings and objective measures of employee creativity, some studies have found varying results, and still others have found that results vary depending on what particular objective measures are used (e.g., Tierney et al., 1999). For example, in an examination of the relations between several indicators of employee creativity and measures of job complexity and leadership style, Oldham and Cummings (1996) found similar results for patent disclosures and supervisory ratings of creativity. However, a different pattern of results emerged for the number of ideas contributed to the organization's suggestion program. These results suggest that for certain jobs or in certain organizations, different measures of creativity converge, while in other kinds of jobs and in other organizations, different measures tap different types or dimensions of creativity. More research is needed to examine utilities of subjective vs. objective measures of creativity, and among different objective measures. 
Finally, as mentioned earlier, the creativity literature has primarily focused on creative outcomes. As researchers turn more attention to studying the creative process itself, valid and reliable process measures need to be developed (Gilson et al., in press).

\section{Team Creativity}

As our review highlights, most earlier research has focused on antecedents of individual employee creativity. However, teams are increasingly responsible for work performed in organizations (Sundstrom, 1999). Thus, it is important to address the conditions that contribute to the creativity of teams. To date, little empirical work has been conducted on this topic, although there is a large body of work on group brainstorming, team innovation, and performance on tasks requiring creative solutions that can provide some insights (see Paulus, 2000; Polzer, Milton \& Swann, 2002; Sosik, Avolio \& Kahai, 1998; Sutton \& Hargadon, 1996; West \& Farr, 1990).

In general, the few studies that have focused on team creativity (e.g., Gilson \& Shalley, 2004; Pirola-Merlo \& Mann, 2004; Taggar, 2001, 2002) have followed an input-processoutcome model that is dominant in research on teams (e.g., Cohen \& Bailey, 1997). For example, a few studies have focused on how team processes impact team creativity (e.g., Nemiro, 2002). Leenders, van Engelen and Kratzer (2003) found that for new product development teams a moderate frequency of communication was best for creativity. This allowed team members to share their ideas and have a constructive dialogue, while (a) not becoming distracted by the amount of information exchanged and (b) still having the cognitive ability to focus on the value of that information. Furthermore, they found that a low level of communication centralization was best for team creativity because ideas were not being filtered through just one or two of the members. Instead the majority of team members were aware of the different opinions being shared and no one member was dominating the creative process.

Taggar (2002) investigated the interaction between team members' individual disposition to be creative (e.g., cognitive ability, openness to experience, and conscientiousness) and team creativity relevant processes (e.g., involving others, addressing conflict, and effective communication) on the creativity of products produced by college student teams. $\mathrm{He}$ found the highest creativity occurred in teams that had creative members and high levels of creativity-relevant processes. When groups had a low incidence of team creativity-relevant processes, this neutralized the effect of having highly creative members, while having groups with less creative members neutralized the effects of high levels of team creativity relevant processes.

Gilson and Shalley (2004) studied antecedents to teams engaging in creative processes by examining task design features, attitudes toward team activities, and team characteristics and interactions. They found that more creative teams were those that perceived that they were working on jobs with high task interdependence and that their tasks required high levels of creativity. Also, teams high on shared goals, that valued participative problem solving, and had a climate supportive of creativity were more creative. Finally, members of the more creative teams had moderate amounts of tenure and spent more time socializing with each other, inside and outside of work. 
More research is now needed on team creativity. For example, previous studies have demonstrated that team personality composition (e.g., extraversion, openness to experience, conscientiousness) has a significant impact on team performance on creative problemsolving tasks (e.g., Barry \& Stewart, 1997; McCrae, 1987). Research is now needed to determine which personality dimensions are particularly relevant to team creativity and what percentage of team members should score high on such dimensions if creativity is to be maximized. For example, is it desirable for all members of a team to score high on openness to experience, or might it be preferable to have a few members of each team score high on each of the FFM personality dimensions?

Previous research also has shown that demographic diversity might contribute to performance on problem solving tasks by increasing constructive conflict and the number of unique ideas that are brought to bear on the tasks (see Milliken, Bartel \& Kurtzberg, 2003). Work is now needed to investigate the effects of diversity on the creativity of products generated by teams. For example, what particular demographic characteristics are most relevant, and is more diversity on each likely to boost team creativity? Work is also needed to understand the processes (e.g., Gilson \& Shalley, 2004) that may help convert personality and demographic diversity to creativity in teams. Finally, research is needed that examines the processes that may be appropriate for different stages of a team's life cycle. For example, Ford and Sullivan (2004) argue that the value of novel proposals changes at different stages of a project team's life cycle.

\section{Conclusion}

Throughout this article we have discussed creativity as though it were a desirable outcome that had many benefits for organizations (e.g., transferring ideas to other employees for their own use and serving as raw material for later organizational innovations). However, few studies have systematically investigated these potential benefits, and it is not yet clear that boosting creativity at work will necessarily result in more innovative organizations that respond effectively to dynamic market conditions. Research is needed that addresses these issues. For example, research is needed that investigates the nature of creative ideas (e.g., radical vs. incremental) that are most likely to be implemented at the organization level. Also work is needed that examines the organizational conditions and managerial activities that facilitate the conversion of ideas into actual innovations in the organization.

In addition to research on the creativity-innovation connection, work is needed to determine if there are negative, unintended consequences of creativity that offset any possible benefits. Few studies have directly examined this possibility, yet it is reasonable to expect that the production of creative ideas may have unintended effects on other employees or processes in the organization (Janssen, Van der Vliert \& West, 2004). For example, it is conceivable that a creative idea developed by one employee may involve changes in work processes that, if implemented, could result in fewer opportunities for other employees in the organization. Or, individuals might expend so much energy developing new ideas that they have little energy remaining for completing their normal, day-to-day assignments. Similarly, when ideas are transferred or made available to other employees, these ideas might distract the attention of the other employees causing them to attend less to their regular 
duties than to the ideas they are considering. Hopefully, long-term, longitudinal studies will allow us to determine the benefits and costs of creativity for the organization and its employees.

Also, little research has focused on what happens once creative ideas or solutions are generated or under what conditions individuals choose to try to be creative. For example, Ford (1996) suggested that creative and habitual actions are competing behavioral options for an individual. Research is needed to understand more fully under what conditions individuals choose to take creative action rather than sticking to more routine behaviors. In addition, since creativity involves the development of novel and useful ideas, how does being creative at work relate to other aspects of performance that may be more related to reducing variation in behaviors across employees? A recent study has begun to address this issue and found that despite the seemingly contradictory nature of using creative vs. standardized procedures, they actually had complementary effects on performance and customer satisfaction (Gilson et al., in press). In addition, research has not focused on determining under what conditions creative ideas are more likely to be recognized and valued, and when they are overlooked or ignored. For example, creativity's success has been proposed to depend on the capabilities, pressures, resources, and sociotechnical system in which employees work (e.g., Csikszentmihalyi, 1999; Mumford, Scott, Gaddis \& Strange, 2002).

Finally, expanding the range of personal and contextual variables examined that might affect the incidence of creativity at work would be beneficial for a better understanding of the antecedents of creativity. As we hope our review highlights, there is now a need for the development of a more comprehensive model of employee creativity that incorporates both what we already know about creativity at work, as well as the new directions discussed. Research of this type should allow us to have a better understanding of employee creativity, the overall value of creativity, and the organizational resources that should be devoted to managing it.

\section{References}

Aiello, J. R., De Risi, D. T., Epstein, Y. M., \& Karlin, R. A. 1977. Crowding and the role of interpersonal distance preference. Sociometry, 40: 271-282.

Amabile, T. M. 1979. Effects of external evaluation on artistic creativity. Journal of Personality and Social Psychology, 37: 221-233.

Amabile, T. M. 1996. Creativity in context. Boulder, CO: Westview.

Amabile, T. M., \& Conti, H. 1999. Changes in the work environment for creativity during downsizing. Academy of Management Journal, 42: 630-640.

Amabile, T. M., Conti, R., Coon, H., Lazenby, J., \& Herron, M. 1996. Assessing the work environment for creativity. Academy of Management Journal, 39: 1154-1184.

Amabile, T. M., Goldfarb, P., \& Brackfield, S. C. 1990. Social influences on creativity: Evaluation, coaction, and surveillance. Creativity Research Journal, 3: 6-21.

Amabile, T. M., \& Gryskiewicz, N. D. 1989. The creative environment scales: Work environment inventory. Creativity Research Journal, 2: 231-252.

Amabile, T. M., Hadley, C. N., \& Kramer, S. J. 2002. Creativity under the gun. Harvard Business Review, 80: 52-61.

Amabile, T. M., Hennessey, B. A., \& Grossman, B. S. 1986. Social influences on creativity: The effects of contracted-for reward. Journal of Personality and Social Psychology, 50: 14-23. 
Amabile, T. M., Schatzel, E. A., Moneta, G. B., \& Kramer, S. J. 2004. Leader behaviors and the work environment for creativity: Perceived leader support. Leadership Quarterly, 15: 5-32.

Anderson, N., De Dreu, C. K. W., \& Nijstad, B. A. 2004. The routinization of innovation research: A constructively critical review of the state-of-the-science. Journal of Organizational Behavior, 25: 147-173.

Andrews, F. M., \& Farris, F. 1967. Supervisory practices and innovation in scientific teams. Personnel Psychology, 20: 497-575.

Andrews, F. M., \& Farris, G. F. 1972. Time pressure and performance of scientists and engineers: A five year panel study. Organizational Behavior and Human Performance, 8: 185-200.

Andrews, J., \& Smith, D. C. 1996. In search of the marketing imagination: Factors affecting the creativity of marketing programs for mature products. Journal of Marketing Research, 33: 174-187.

Baer, M., Oldham, G. R., \& Cummings, A. 2003. Rewarding creativity: When does it really matter? Leadership Quarterly, 14: 569-586.

Bandura, A. 1977. Social learning theory. Englewood Cliffs, NJ: Prentice-Hall.

Bandura, A. 1986. Social foundations of thought and action: A social cognitive theory. Englewood Cliffs, NJ: Prentice-Hall.

Barron, F., \& Harrington, D. M. 1981. Creativity, intelligence, and personality. Annual Review of Psychology, 32 : 439-476.

Barry, B., \& Stewart, G. L. 1997. Composition, process, and performance in self managed groups: The role of personality. Journal of Applied Psychology, 82: 62-78.

Bartis, S., Szymanski, K., \& Harkins, S. G. 1988. Evaluation and performance: A two edged knife. Personality and Social Psychology Bulletin, 14: 242-251.

Burke, M. J., Brief, A., George, J., Roberson, L., \& Webster, J. 1989. Measuring affect at work: Confirmatory analyses of competing mood structures with conceptual linkage to cortical regulatory systems. Journal of Personality and Social Psychology, 57: 1091-1102.

Carson, P. P., \& Carson, K. D. 1993. Managing creativity enhancement through goal setting and feedback. Journal of Creative Behavior, 27: 36-45.

Cha, J. H. 1994. Aspects of individualism and collectivism in Korea. In U. Kim \& H. Triandis (Eds.), Individualism and collectivism: Theory, method, and applications: 157-174. Thousand Oaks, CA: Sage.

Cheek, J. M., \& Stahl, S. S. 1986. Shyness and verbal creativity. Journal of Research in Personality, 20: 51-61.

Cohen, S. G., \& Bailey, D. E. 1997. What makes teams work: Group effectiveness research from the shop floor to the executive suite. Journal of Management, 23: 239-290.

Costa, P. T., \& McCrae, R. R. 1992. Revised NEO Personality Inventory (NEO PI-R) and NEO Five-Factor Inventory (NEO-FFI) professional manual. Odessa, FL: Psychological Assessment Resources.

Csikszentmihalyi, M. 1997. Creativity: Flow and the psychology of discovery and invention. New York: Harper Collins.

Csikszentmihalyi, M. 1999. Implications of a system perspective for the study of creativity. In R. Sternberg (Ed.), Handbook of creativity: 313-328. New York: Cambridge University Press.

Cummings, A., \& Oldham, G. R. 1997. Enhancing creativity: Managing work contexts for the high potential employee. California Management Review, 40: 22-38.

Deci, E. L., Connell, J. P., \& Ryan, R. M. 1989. Self-determination in a work organization. Journal of Applied Psychology, 74: 580-590.

Deci, E. L., \& Ryan, R. M. 1985. Intrinsic motivation and self-determination in human behavior. New York: Plenum.

Drazin, R., Glynn, M., \& Kazanjian, R. 1999. Multilevel theorizing about creativity in organizations: A sensemaking perspective. Academy of Management Review, 24: 286-307.

Eisenberger, R. 1992. Learned industriousness. Psychological Review, 99: 248-267.

Eisenberger, R., \& Armeli, S. 1997. Can salient reward increase creative performance without reducing intrinsic creative interest? Journal of Personality and Social Psychology, 72: 652-663.

Eisenberger, R., \& Rhoades, L. 2001. Incremental effects of rewards on creativity. Journal of Personality and Social Psychology, 81: 728-741.

England, G. W., \& Harpaz, I. 1990. How working is defined: National contexts and demographic and organizational role influences. Journal of Organizational Behavior, 11: 253-266.

Farmer, S. M., Tierney, P., \& Kung-McIntyre, K. 2003. Employee creativity in Taiwan: An application of role identity theory. Academy of Management Journal, 46: 618-630. 
Feist, G. J. 1998. A meta-analysis of personality in scientific and artistic creativity. Personality and Social Psychology Review, 4: 290-309.

Feist, G. J. 1999. The influence of personality on artistic and scientific creativity. In R. Sternberg (Ed.), Handbook of creativity: 272-296. New York: Cambridge University Press.

Ford, C. M. 1996. A theory of individual creative action in multiple social domains. Academy of Management Review, 21: 1112-1142.

Ford, C., \& Sullivan, D. M. 2004. A time for everything: How the timing of novel contributions influences project team outcomes. Journal of Organizational Behavior, 25: 279-292.

Frese, M., Teng, E., \& Wijnen, C. J. 1999. Helping to improve suggestion systems: Predictors of making suggestions in companies. Journal of Organizational Behavior, 20: 1139-1155.

George, J. M., \& Brief, A. P. 1992. Feeling good-doing good: A conceptual analysis of the mood at workorganizational spontaneity relationship. Psychological Bulletin, 112: 310-329.

George, J. M., \& Zhou, J. 2001. When openness to experience and conscientiousness are related to creative behavior: An interactional approach. Journal of Applied Psychology, 86: 513-524.

George, J. M., \& Zhou, J. 2002. Understanding when bad moods foster creativity and good ones don't: The role of context and clarity of feelings. Journal of Applied Psychology, 87: 687-697.

Gilson, L. L., Mathieu, J. E., Shalley, C. E., \& Ruddy, T. M. (in press). Creativity and standardization: Complementary or conflicting drivers of team effectiveness? Academy of Management Journal..

Gilson, L. L., \& Shalley, C. E. 2004. A little creativity goes a long way: An examination of teams' engagement in creative processes. Journal of Management, 30: 453-470.

Gough, H. G. 1979. A creative personality scale for the Adjective Check List. Journal of Personality and Social Psychology, 37: 1398-1405.

Hackman, J. R., \& Oldham, G. R. 1980. Work redesign. Reading, MA: Addison-Wesley.

Hatcher, L., Ross, T. L., \& Collins, D. 1989. Prosocial behavior, job complexity, and suggestion contribution under gainsharing plans. Journal of Applied Behavioral Science, 25: 231-248.

Hirt, E. R., Levine, G. M., McDonald, H. E., \& Melton, R. J. 1997. Journal of Experimental Social Psychology. The role of mood in quantitative and qualitative aspects of performance: Single or multiple mechanisms? 33: 602-629.

Isen, A. M. 1999. On the relationship between affect and creative problem solving. In S. Russ (Ed.), Affect, creative experience and psychological adjustment: 3-17. Philadelphia: Brunner/Mazel.

Janssen, O., Van der Vliert, E., \& West, M. 2004. The bright and dark sides of individual and group innovation: A special introduction. Journal of Organizational Behavior, 25: 129-145.

Kaufmann, G., \& Vosburg, S. K. 1997. "Paradoxical" mood effects on creative problem-solving. Cognition and Emotion, 11: 151-170.

Kazanjian, R. K., Drazin, R., \& Glynn, M. A. 2000. Creativity and technological learning: the roles of organization architecture and crisis in large-scale projects. Journal of Engineering and Technology Management, 17: 273-298.

Keller, R. T. 1986. Predictors of the performance of project groups in R\&D organizations. Academy of Management Journal, 29: 715-726.

Kelly, J. R., \& McGrath, J. E. 1985. Effects of time limits and task types on task performance and interaction of four-person groups. Journal of Personality and Social Psychology, 49: 395-497.

Kirton, M. J. 1976. Adaptors and innovators: A description and measure. Journal of Applied Psychology, 61: $622-629$.

Kirton, M. J. 1994. Adaptors and innovators: Styles of creativity and problem solving (2nd ed.). New York: Routledge.

Kristof, A. L. 1996. Person-organization fit: An integrative review of its conceptualizations, measurement and implications. Personnel Psychology, 49: 1-49.

Kruglanski, A. W., Friedman, I., \& Zeevi, G. 1971. The effects of extrinsic incentive on some qualitative aspects of task performance. Journal of Personality, 39: 606-617.

Kwang, N. A., \& Rodrigues, D. 2002. A big-five personality profile of the adaptor and innovator. Journal of Creative Behavior, 36: 254-268.

Leenders, R. T h. A. J., van Engelen, J. M. L., \& Kratzer, J. 2003. Virtuality, communication, and new product team creativity: A social network perspective. Journal of Engineering and Technology Management, 20: 6992. 
Lowe, E. A., \& Taylor, W. G. K. 1986. Creativity in life sciences research. R\&D Management, 16: 4561.

Madjar, N., \& Oldham, G. R. 2002. Preliminary tasks and creative performance on a subsequent task: Effects of time on preliminary tasks and amount of information about the subsequent task. Creativity Research Journal, 14: 239-251.

Madjar, N., Oldham, G. R., \& Pratt, M. G. 2002. There's no place like home? The contributions of work and nonwork creativity support to employees' creative performance. Academy of Management Journal, 45: 757-767.

Mainemelis, C. 2001. When the muse takes it all: A model for the experience of timelessness in organizations. Academy of Management Review, 26: 548-565.

Masten, W. G., \& Caldwell-Colbert, A. T. 1987. Relationship of originality to Kirton's scale for innovators and adaptors. Psychological Reports, 61: 411-416.

McCrae, R. R. 1987. Creativity, divergent thinking, and openness to experience. Journal of Personality and Social Psychology, 52: 1258-1265.

McCrae, R. R., \& Costa, P. T. 1997. Conceptions and correlates of Openness to Experience. In R. Hogan, J. Johnson, \& S. Briggs (Eds.), Handbook of personality psychology: 825-847. San Diego, CA: Academic Press.

McGlynn, R. P., Gibbs, M. E., \& Roberts, S. J. 1982. Effects of cooperative versus competitive set and coaction on creative responding. Journal of Social Psychology, 118: 281-282.

Milliken, F. J., Bartel, C. A., \& Kurtzberg, T. 2003. Diversity and creativity in work groups: A dynamic perspective on the affective and cognitive processes that link diversity and performance. In P. Paulus \& B. Nijstad (Eds.), Group creativity: 32-62. New York: Oxford University Press.

Mumford, M. D. 2000. Managing creative people: Strategies and tactics for innovation. Human Resources Management Review, 10: 313-351.

Mumford, M. D., Baughman, W. A., Maher, M. A., Costanza, D. P., \& Supinski, E. P. 1997. Process based measures of creative problem solving skills: 4. Category combination. Creativity Research Journal, 10: 59-71.

Mumford, M. D., \& Gustafson, S. B. 1988. Creativity syndrome: Integration, application, and innovation. Psychological Bulletin, 103: 27-43.

Mumford, M. D., Scott, G. M., Gaddis, B., \& Strange, J. M. 2002. Leading creative people: Orchestrating expertise and relationships. Leadership Quarterly, 13: 705-750.

Nemiro, J. E. 2002. The creative process in virtual teams. Creativity Research Journal, 14: 69-83.

Nonaka, I. 1991. The knowledge-creating company. Harvard Business Review, 69: 96-104.

Oldham, G. R. 2002. Stimulating and supporting creativity in organizations. In S. Jackson, M. Hitt, \& A. DeNisi (Eds.), Managing knowledge for sustained competitive advantage: 243-273. San Francisco: Jossey-Bass.

Oldham, G. R., \& Cummings, A. 1996. Employee creativity: Personal and contextual factors at work. Academy of Management Journal, 39: 607-634.

Oldham, G. R., Cummings, A., \& Zhou, J. 1995. The spatial configuration of organizations. In G. Ferris (Ed.), Research in personnel and human resources management: vol. 13. 1-37. Greenwich, CT: JAI Press.

Paulus, P. B. 2000. Groups, teams, and creativity: The creative potential of idea-generating groups. Applied Psychology-An International Review, 49: 237-262.

Perry-Smith, J. E., \& Shalley, C. E. 2003. The social side of creativity: A static and dynamic social network perspective. Academy of Management Review, 28: 89-106.

Piedmont, R. L., McCrae, R. R., \& Costa, P. T. 1991. Adjective checklist scales and the five-factor model. Journal of Personality and Social Psychology, 60: 630-637.

Pirola-Merlo, A., \& Mann, L. 2004. The relationship between individual creativity and team creativity: Aggregating across people and time. Journal of Organizational Behavior, 25: 235-257.

Polzer, J. T., Milton, L. P., \& Swann, W. B. 2002. Capitalizing on diversity: Interpersonal congruence in small work groups. Administrative Science Quarterly, 47: 296-325.

Redmond, M. R., Mumford, M. D., \& Teach, R. 1993. Putting creativity to work: Effects of leader behavior on subordinate creativity. Organizational Behavior and Human Decision Processes, 55: 120-151.

Reiter-Palmon, R., \& Illies, J. J. 2004. Leadership and creativity: Understanding leadership from a creative problemsolving perspective. Leadership Quarterly, 15: 55-77.

Reiter-Palmon, R., Mumford, M. D., Boes, J. O., \& Runco, M. A. 1997. Problem construction and creativity: The role of ability, cue consistency, and active processing. Creativity Research Journal, 10: 9-23.

Rodan, S., \& Galunic, C. 2004. More than network structure: How knowledge heterogeneity influences managerial performance and innovativeness. Strategic Management Journal, 25: 541-562. 
Roos, P. A., \& Treiman, D. J. 1980. Worker functions and work traits for the 1970 U.S. census classification. In A. Miller (Ed.), Work, jobs and occupations: 336-389. Washington, DC: National Academy Press.

Schaefer, C. E. 1969. The prediction of creativity from a biographical inventory. Educational and Psychological Measurement, 29: 431-437.

Schneider, B. 1987. The people make the place. Personnel Psychology, 40: 437-453.

Schwartz, S. H. 1992. Universals in the content and structure of values: Theory and empirical tests in 20 countries. In M. Zanna (Ed.), Advances in experimental social psychology: vol. 25. 1-65. New York: Academic Press.

Scratchley, L. S., \& Hakstian, A. R. 2000. The measurement and prediction of managerial creativity. Creativity Research Journal, 13: 367-384.

Shalley, C. E. 1991. Effects of productivity goals, creativity goals, and personal discretion on individual creativity. Journal of Applied Psychology, 76: 179-185.

Shalley, C. E. 1995. Effects of coaction, expected evaluation, and goal setting on creativity and productivity. Academy of Management Journal, 38: 483-503.

Shalley, C. E., \& Gilson, L. L. 2004. What leaders need to know: A review of social and contextual factors that can foster or hinder creativity. Leadership Quarterly, 15: 33-53.

Shalley, C. E., Gilson, L. L., \& Blum, T. C. 2000. Matching creativity requirements and the work environment: Effects on satisfaction and intention to leave. Academy of Management Journal, 43: 215-223.

Shalley, C. E., \& Oldham, G. R. 1997. Competition and creative performance: Effects of competitor presence and visibility. Creativity Research Journal, 10: 337-345.

Shalley, C. E., \& Perry-Smith, J. E. 2001. Effects of social-psychological factors on creative performance: The role of informational and controlling expected evaluation and modeling experience. Organizational Behavior and Human Decision Processes, 84: 1-22.

Shin, S., \& Zhou, J. 2003. Transformational leadership, conservation, and creativity: Evidence from Korea. Academy of Management Journal, 46: 703-714.

Soriano de Alencar, E., \& Bruno-Faria, M. 1997. Characteristics of an organizational environment which stimulate and inhibit creativity. Journal of Creative Behavior, 3: 271-281.

Sosik, J. J., Avolio, B. J., \& Kahai, S. S. 1998. Inspiring group creativity: Comparing anonymous and identified electronic brainstorming. Small Group Research, 29: 3-31.

Stahl, M. J., \& Koser, M. C. 1978. Weighted productivity in R\&D: Some associated individual and organizational variables. IEEE Transactions on Engineering Management, EM-25: 20-24.

Staw, B. M., Calder, B. J., Hess, R. K., \& Sandelands, L. E. 1980. Intrinsic motivation and norms about payment. Journal of Personality, 48: 1-14.

Stein, M. I. 1967. Creativity and culture. In R. Mooney \& T. Razik (Eds.), Explorations in creativity: 109-119. New York: Harper.

Sundstrom, E. 1986. Work places. London: Cambridge Press.

Sundstrom, E. 1999. The challenges of supporting work team effectiveness. In Supporting work team effectiveness. San Francisco, CA: Jossey-Bass (pp. 3-23).

Sutton, R. I., \& Hargadon, A. 1996. Brainstorming groups in context: Effectiveness in a product design firm. Administrative Science Quarterly, 41: 685-734.

Szymanski, K., \& Harkins, S. G. 1992. Self-evaluation and creativity. Personality and Social Psychology Bulletin, 18: 259-265.

Taggar, S. 2001. Group composition, creative synergy, and group performance. Journal of Creative Behavior, 35 : 261-286.

Taggar, S. 2002. Individual creativity and group ability to utilize individual creative resources: A multilevel model. Academy of Management Journal, 45: 315-330.

Tierney, P., \& Farmer, S. M. 2002. Creative self-efficacy: Potential antecedents and relationship to creative performance. Academy of Management Journal, 45: 1137-1148.

Tierney, P., \& Farmer, S. M. 2004. The Pygmalion process and employee creativity. Journal of Management, 30 : 413-432.

Tierney, P., Farmer, S. M., \& Graen, G. B. 1999. An examination of leadership and employee creativity: The relevance of traits and relationships. Personnel Psychology, 52: 591-620.

Torrance, E. P. 1965. Rewarding creative behavior. Englewood Cliffs, NJ: Prentice-Hall.

Unsworth, K. 2001. Unpacking creativity. Academy of Management Review, 26: 289-297. 
Utman, C. H. 1997. Performance effects of motivational state: A meta-analysis. Personality and Social Psychology Review, 1: 170-182.

Van Dyne, L., Jehn, K. A., \& Cummings, A. 2002. Differential effects of strain on two forms of work performance: Individual employee sales and creativity. Journal of Organizational Behavior, 23: 57-74.

Vincent, A. S., Decker, B. P., \& Mumford, M. D. 2002. Divergent thinking, intelligence \& expertise: A test of alternative models. Creativity Research Journal, 14: 163-178.

West, M. A., \& Farr, J. L. 1990. Innovation at work. In M. West \& J. Farr (Eds.), Innovation and creativity at work: Psychological and organizational strategies: 3-13. Chichester, England: Wiley.

Woodman, R. W., Sawyer, J. E., \& Griffin, R. W. 1993. Toward a theory of organizational creativity. Academy of Management Review, 18: 293-321.

Zhou, J. 1998. Feedback valence, feedback style, task autonomy, and achievement orientation: Interactive effects on creative performance. Journal of Applied Psychology, 83: 261-276.

Zhou, J. 2003. When the presence of creative coworkers is related to creativity: Role of supervisor close monitoring, developmental feedback, and creative personality. Journal of Applied Psychology, 88: 413-422.

Zhou, J., \& George, J. M. 2001. When job dissatisfaction leads to creativity: Encouraging the expression of voice. Academy of Management Journal, 44: 682-696.

Zhou, J., \& George, J. M. 2003. Awakening employee creativity: The role of leader emotional intelligence. Leadership Quarterly, 14: 545-568.

Zhou, J., \& Oldham, G. R. 2001. Enhancing creative performance: Effects of expected developmental assessment strategies and creative personality. Journal of Creative Behavior, 35: 151-167.

Zhou, J., \& Shalley, C. E. 2003. Research on employee creativity: A critical review and directions for future research. In J. Martocchio (Ed.), Research in personnel and human resource management: 165-217. Oxford, England: Elsevier.

Christina E. Shalley is a Professor of Organizational Behavior and Human Resource Management in the College of Management at the Georgia Institute of Technology. She received her Ph.D. in Business Administration from the University of Illinois at Urbana-Champaign. Her current research interests focus on investigating the effects of various social and contextual factors in enhancing and stifling employee creativity and examining ways to structure jobs and the work environment to support creative work.

Jing Zhou is an Associate Professor of Management in the Jesse H. Jones Graduate School of Management at Rice University. She received her Ph.D. from the University of Illinois at Urbana-Champaign. Her current research interests include contextual factors that promote or inhibit employee creative performance. Prior to joining the Jones School at Rice, she served on the faculty in the Management Department at the Mays Business School at Texas A\&M University.

Greg R. Oldham is C. Clinton Spivey Distinguished Professor of Business Administration, Professor of Labor and Industrial Relations, and Associate Dean of Faculty in the College of Business at the University of Illinois at Urbana-Champaign. He received his Ph.D. from Yale University. His current research focuses on the contextual and personal conditions that prompt the development and expression of creative ideas in work organizations. 